\title{
INFLUENCE OF ENIVIRONMENTAL CONTAMINATION ON CHROMIUM AND ZINC CONTENT OF SELECTED EDIBLE VEGETABLES: SAFETY AND NUTRITIONAL ASPECT
}

\author{
BS Jayasinghe and MIFP Jayawardene \\ Department of Biochemistry, Faculty of Medical Sciences, \\ University of Sri Jayewardenepura, Nugegoda
}

\begin{abstract}
The content of heavy metals in vegetables may be increased by contamination through various sources. It is therefore important to test and maintain the quality of vegetables in terms of heavy metals, in view of recent recommendations to increase their intake. People who are not excessively exposed in their occuy)ation to environmental trace element contamination comes into contact with these pollutants through the contaminated foods and water they ingest. Vegetables are the first link in the rophic chain affected by this contamination.

Chromium and Zinc are essential elements required for normal functions in plants and animals. Chromium has a complicated envirc nmental chemistry and plays a role as both a nutrient and a toxic agent, also as a known carcinogen. Chromium enters the environment as a result of effluent discharge from steel work, electroplating, tanning industry, oxidative dyeing, chemical industries, and cooling water towers. Zinc is biologically one of the most important metal and is apparently necessary to all forms of life. Although it is not very toxic to animals zinc is phytotoxic and soil can be "poisonec " by exposure to zinc smelting or from application of zinc rich sewage sludge. Zinc oxide is used as an accelerating and activating agent for hardening rubber product. Tires and tire wear is a major vector for the transfer of $\mathbf{Z n}$ to the environment.

In this study the $\mathrm{Cr} \& \mathrm{Zn}$ content of edible vegetables commonly grown and sold in Colombo, Kandy \& Balangoda were determined by flame atomic absorption spectrometer(FAAS) after dry ashing. For the dry ashing procedure, dried samples were used and ashed at $4500 \mathrm{C}$ overnight. Ashed samples were dissolved in $01 \mathrm{M} \mathrm{HNO}$. Extensive validation of the proposed method was carried out by the standard addition method.

In the FAAS used measurement collit be made over a linear range between $0.119-5 \mu \mathrm{g} / \mathrm{mI}$ for $\mathrm{Cr}$ and $0.0374-1.64 \mu \mathrm{g} / \mathrm{mI} \mathrm{Zn}$ respectively. $\mathrm{Cr}$ and $\mathrm{Zn}$ of Colombo samples varied from 0.0079$0.2044 \mathrm{mg} / \mathrm{kg}$ and $1.13-3.59 \mathrm{mg} / \mathrm{Kg}$ respectively. Both $\mathrm{Cr}$ and $\mathrm{Zn}$ levels in Balangoda samples varied from $0.006-0.0468 \mathrm{mg} / \mathrm{K} \varepsilon$, tespectively. Kandy samples also gave similar values as Balangoda samples.

It is seen that the leafy vegetable stimples obtained from Colombo had a higher mean level of $\mathrm{Cr}$ and $\mathrm{Zn}$ when compared to those ob ained from Kandy and Balangoda. Tubers and roots gave lower mean level of $\mathrm{Cr}$ and $\mathrm{Zn}$ han leafy vegetables. Therefore it confirms the role of environmental influence to the cortent of these elements, which could be attributed to the contaminated soil, dust, sewage or viater sources. Results obtained in this study seem to suggest that environmental contamination plays a role in the $\mathrm{Cr}$ content of edible vegetables.
\end{abstract}

